\title{
SOLIDARIOS FRENTE A COLABORADORES: \\ antropología y movimiento indígena en el Cauca en las décadas de I970 y I980
}

\author{
Mauricio Caviedes \\ ESTUDIANTE DE MAESTRÍA EN ANTROPOLOGÍA, \\ UNIVERSIDAD NACIONAL DE COLOMBIA \\ mcaviedes@hotmail.com
}

\begin{abstract}
Resumen
[ STE ARTíCULO EXAMINA LA RELACIÓN ENTRE INTELECTUALES MILITANTES Y MOVIMIENTO [ indígena en el departamento del Cauca, Colombia, durante las décadas de I970 y I980. Esta relación fue el resultado de un momento de confluencia de diferentes corrientes ideológicas, tradicionalmente opuestas, las cuales se redefinieron entre sí a partir de su comunión en torno a la transformación de las sociedades indígenas y la sociedad nacional. Al mismo tiempo, varios de estos intelectuales, no necesariamente ligados a la antropología, hicieron parte de un proceso que impacta las ciencias sociales, entre ellas la antropología, transformando a su vez su praxis y la manera de entender la disciplina.

PALABRAS CLAVE: movimiento indígena, intelectuales militantes, praxis disciplinaria, Cauca (Colombia).
\end{abstract}

\begin{abstract}
T HIS ARTICLE EXAMINES THE RELATIONSHIP BETWEEN THE INDIGENOUS MOVEMENT IN THE CAUca department of Colombia and militant intellectuals who supported it during the I970's and I980's. This relationship was the result of a moment in which different and traditionally opposed ideological currents, redefined each other on the basis of shared interests regarding the transformation of the indigenous and national societies. At the same time, these intellectuals, not all of them anthropologists, made part of a process influencing the social sciences, amongst them anthropology, that transformed disciplinary practice and the way the discipline was conceived.

KEY wORDS: indigenous movement, militant intellectuals, social sciences, disciplinary practice, Cauca (Colombia).
\end{abstract}

Revista Colombiana de Antropología

Volumen 38, enero-diciembre 2002, pp. 237-260 


\section{INTRODUCCIÓN}

STE ENSAYO ${ }^{1}$ ES RESULTADO DE MI TESIS DE GRADO COMO ANTROPÓLO- go, pero no un resumen de ella. Al escribirla mi intención era L argumentar cómo el movimiento indígena había alimentado a la antropología al mismo tiempo que la antropología al movimiento, resultado de lo cual ambos se habrían transformado. Pero

I. Este trabajo obtuvo el segundo puesto del conmi conocimiento del movimienI. Este trabajo obtuvo el segundo
curso de ensayo ICANH 60 años. to indígena provenía de lo que había leído sobre él en la universidad. Con el tiempo pude acercarme a algunos resguardos indígenas, en donde conocí a líderes de las recuperaciones logradas con el apoyo del Consejo Regional Indígena del Cauca (Cric), entrevisté también algunos miembros del movimiento solidario que habían acompañado la lucha liderada por los resguardos de Guambía y Jambaló, quienes en cierto momento se desligaron del Cric y llegaron a conformar una organización paralela -con el apoyo de indígenas de otras zonas del país-, que con el tiempo adquirió el nombre de Movimiento de Autoridades Indígenas de Colombia, y busqué un contraste con la versión de los solidarios en los testimonios de colaboradores no indígenas del Cric. Mientras lo hacía mis interlocutores demandaban de mí una posición respecto a las diferencias entre ambos grupos y por mucho tiempo temí asumirla. Descubrir mi propia posición hizo parte de darme cuenta que la antropología que buscaba en interacción con el movimiento indígena no fue un discurso elaborado por los antropólogos, sino una reflexión llevada a cabo por quienes se involucraron con el movimiento: indígenas y solidarios o colaboradores, que en algunos casos eran antropólogos y en muchos otros no. Por eso, lo que trato de presentar aquí no es la versión última de los sucesos que definieron las luchas indígenas en el Cauca, ni la apología de solidarios o colaboradores, como tampoco la versión definitiva de lo que todos los antropólogos hacen ahora como resultado de la lucha de aquellos años.

En el Cauca, entre indígenas, solidarios y colaboradores se elaboró una posición frente a la relación de poder entre sociedad nacional y sociedades no occidentales, se reflexionó frente a la posibilidad de que toda una tradición cultural desapareciese o no bajo el poder impuesto por otra e, incluso, se desarrollaron estrategias para entender y construir una relación entre sociedad nacional y pueblos indígenas. Es por ello que considero que hay 


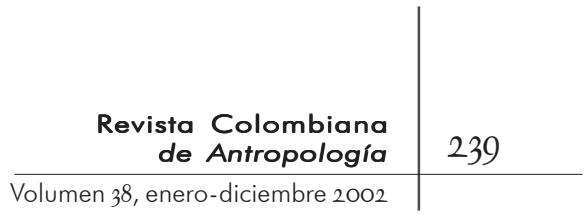

aquí una reflexión sobre las transformaciones de la antropología, no en tanto la historia aquí narrada dé cuenta de la práctica de toda la profesión, sino porque ofrece a la antropología estrategias que permiten trascender tal práctica.

\section{IZQUIERDA Y MOVIMIENTO INDÍGENA}

Oberto Pineda Reconstruye los Pasos DE la historia DEL "INDigenismo revolucionario", intento de incluir al indígena como potenciador de una transformación socialista en el país, en los años 1930, cuando el Partido Comunista postuló a un candidato indígena a la presidencia. Este esfuerzo estaba inspirado en las propuestas de Mariátegui y en el reconocimiento del potencial revolucionario de las sociedades indígenas (Pineda, I984: 2I3). En Colombia, entre otros, Ignacio Torres Giraldo motivó el vínculo del Partido Comunista con el movimiento indígena (Pineda, I984: 2I8). Dos figuras fundamentales del movimiento indígena representan el destino de esta relación hacia el futuro: Manuel Quintín Lame y José Gonzalo Sánchez; ambos líderes contribuyeron a la consolidación de movimientos de corte obrero (Vasco, 2002: I35). Pero mientras Lame diside (Pineda, I984: 218) Sánchez permanece, evidenciando de un distanciamiento creciente entre las organizaciones de inspiración socialista y el movimiento indígena (Pineda, I984: 2I5-2I6, 2I9-220). Pineda intenta cambiar la imagen de Sánchez como líder que subordinó las formas de organización comunitaria entre indígenas a las condiciones del partido, contradiciendo a lo afirmado un par de años antes por Bonilla, aun cuando lo cierto es que este recrea una imagen que ha permanecido entre las comunidades (Bonilla, I982: 38).

Esta brecha entre la izquierda y el movimiento indígena es la misma que presenta Gros cuando afirma que el proyecto modernizador inherente a la izquierda obligó a que esta contemplase a las comunidades rurales -campesinos y, en especial, indígenas- como fuerzas con potencial revolucionario, al tiempo que atrasadas y subordinadas al proletariado, en tanto la lucha revolucionaria latinoamericana adoptó el modelo cubano (Gros, I99I: I3I, I33). Estas comunidades debían ser reclutadas a la vez que constituían casi un estorbo. Pero con el tiempo en países como Bolivia se planteó una contradicción a la izquierda 
ortodoxa, pues su población indígena cuestionó la imposición de un proyecto político a aquellas comunidades que declaraba representar, a la vez que se convertía, estando entre ellas, en representante del imperialismo que pretendía combatir (Gros, I99I: I49).

Mucho antes que Gros, en un texto que busca fortalecer al movimiento indígena, Guillermo Bonfil Batalla hizo un reclamo bastante específico en el mismo sentido: "Los partidos y las organizaciones nacionales de izquierda, a juzgar por su posición (o, más frecuentemente por su falta de posición), no han logrado aceptar, ni teórica ni prácticamente, el hecho: 'movilización política india'; en realidad, no han aceptado un hecho previo: el indio" (Bonfil, I98r: I6). Lo que hay allí es, justamente, una imagen del indio como un ser encerrado en su resguardo -y en su cultura anacrónica-, aislado de las contradicciones de clase y que debe ser inscrito en el campesinado y subordinado al proletariado mediante el mestizaje. Y esta idea ubica la política indígena de la izquierda ortodoxa junto a la de las clases en el poder (Gros, I99I: I3I; Bonfil, I98I: I6).

Abandonado el indigenismo de los años I920 y I930, las ciencias sociales no proponían ninguna alternativa. La tendencia general de la antropología se afiliaba a la línea de Patzcuaro, originada en México, que entendía también a las comunidades indígenas como souvenirs del pasado y cuya única alternativa era el mestizaje (Gros, I99I: II7; Uribe, I980: 285).

Es curioso, sin embargo, que Rosaldo -junto con Bernsteiny Ortner, encuentran en el marxismo -entre otras corrientes de pensamiento relegadas por las ciencias sociales- la base sobre la que estas replantean en las décadas de 1960 y 1970 su relación con su objeto de estudio. En el doble papel de militantes y académicos emergentes, nuevos investigadores sociales instalaron su crítica de la sociedad en sus propias disciplinas, orientándolas lejos del observador indiferente hacia una práctica comprometida con las comunidades entre las que se desarrollaba su investigación (Rosaldo, I99I: 44; Ortner, I994: 382, 383). La razón por la que para el caso colombiano es importante esta transformación en las ciencias sociales en Estados Unidos es la existencia, en ambos países, de una discusión sobre el desbalance de relaciones de poder entre sectores de la sociedad en "la estructura capitalista nacional e internacional en su conjunto" (Gros, I99I: I32). 


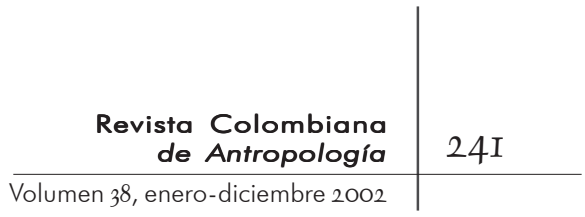

Otros autores arguyen la transformación de la antropología en el país como consecuencia, por un lado, del intento de consolidación del capitalismo en Colombia (Uribe, I980: 288, 296) y, por otro, de la movilización estudiantil inspirada en parte por el marxismo (Uribe, I980: 297, 299), al que también se refiere Jimeno como influencia en el cambio de los paradigmas de la antropología, que resultó en la formulación de un compromiso político del investigador con la reconstrucción de una sociedad nacional que superase la desigualdad social (2000: 173). Pero mientras para Jimeno y Uribe la influencia de la sociología y el marxismo motiva la discusión sobre la posición del investigador, Arocha muestra las dificultades de tal discusión, al plantear que un periodo de "crítica y conflicto", durante los años I970, acercó a los científicos sociales a las reivindicaciones de los "grupos base", desde una perspectiva de los conflictos de clase y la dependencia de Estados Unidos, que derivó también en la adopción de "muchos [antropólogos]" del "materialismo dialéctico como panacea” (Arocha y Friedemann, 1984: 7).

Pero para no presentar esta influencia del pensamiento de izquierda como un estereotipo de la protesta estudiantil estadounidense de Rosaldo, sólo las experiencias de quienes hicieron parte del movimiento indígena en las décadas de 1970 y 1980 permitirán penetrar la atmósfera política de aquel momento, la situación del movimiento indígena frente a otros movimientos sociales y las posibilidades que estos espacios ofrecieron a las ciencias sociales.

\section{SOLIDARIOS VS. COLABORADORES}

\footnotetext{
N N EL TEXTO "PROTESTA SOCIAL Y ESTADO EN EL FRENTE NACIONAL", - Mauricio Archila introduce su análisis evitando definir como constitutivos de un movimiento social tanto las protestas estudiantiles como las indígenas. Sin embargo, dice que llegando a la década de 1970 la importancia de la protesta estudiantil rebasaba, incluso, a la del movimiento obrero y campesino, pero por la pérdida de sus líderes y el desvanecimiento de sus organizaciones -debido a la represión-, volvió a perder relevancia frente al movimiento cívico (I997: 20). Ubica también la importancia del movimiento indígena como resurgiente "al abrigo
} 


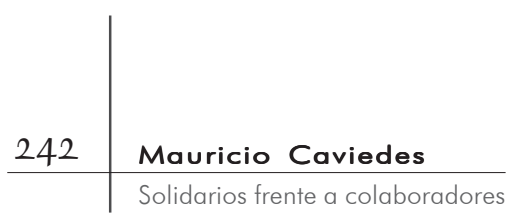

del movimiento campesino" en la década de I970 (I997: I3), pero esta "subordinación” puede deberse a una confusión de Archila, producto del intento de captar al movimiento indígena en un momento en el que -como él mismo anota- apenas empezaba a resurgir.

\section{Hacienda Las Mercedes, DEPARTAMENTO DE CAUCA, I980}

$\bigcup 1$ NA VEZ LOGRADA LA RECUPERACIÓN DE LA HACIENDA LAS MERCEDES, los cabildos de Guambía y Jambaló, organizados en lo que empezaba a tomar forma bajo el nombre del Movimiento de Gobernadores Indígenas en Marcha, estaban preparados para la llegada de una buena cantidad de otros grupos para la "asamblea del núcleo", reunión en la cual el pueblo guambiano se definió como tal, presentando el "Manifiesto guambiano". Pero esta asamblea implicaba la llegada de miembros del comité ejecutivo del Cric, con el que los cabildos de Jambaló y Guambía habían entrado en un conflicto que, aun cuando había nacido en I97I con el Cric mismo, se había intensificado a finales de los años I970, cuando bajo la acusación de lazos con el M-Ig el gobierno había perseguido y encarcelado a los líderes más importantes del Cric. La consecuencia de ello fue la declaración por parte de los grandes terratenientes de que este había muerto. Pero en respuesta a ello un sector del Cric, encabezado por líderes de Guambía y Jambaló, proclamó la continuidad de las luchas en la consigna: "El Cric no ha muerto. El Cric somos las comunidades organizadas y en lucha”. Fue entonces cuando hubo una ruptura clara entre los líderes del comité ejecutivo original, apoyado por un grupo de colaboradores no indígenas, y el segundo sector, con sus propios colaboradores, que habían asumido el nombre de "solidarios" (Bonilla, 2000, entrevista; Gobernadores Indígenas en Marcha, I98I: 53).

Justo en medio de la atmósfera de un proceso crecientemente exitoso de organización indígena, que culminaría con la llegada de Belisario Betancur a la presidencia en 1982, la atención de otros movimientos sociales se había visto obligada a volverse al movimiento indígena, pues tanto movimientos armados como obreros y campesinos entendieron que, a la luz del reconocimiento 


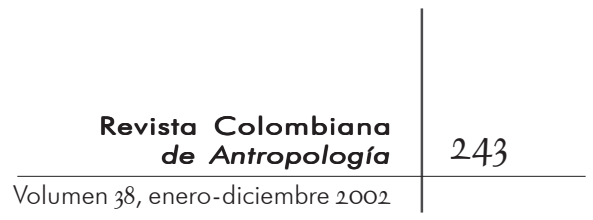

nacional, tendrían que abrirle espacio al movimiento indígena en su discurso (Fayad 2000, entrevista). Fue así como a Las Mercedes llegaron grupos de estudiantes seducidos por el discurso de la solidaridad con el movimiento indígena, como parte del logro de un movimiento popular del que anhelaban hacer parte (Castro y Álvarez, 2000, entrevista). Ello es lo que desata la pequeña historia que presento a continuación, subproducto de una serie de entrevistas que realicé para mi tesis de grado, durante 2000 .

\section{AMOR POR LA REVOLUCiÓN}

(6) EN ESA ÉPOCA yo ESTUdiabA EN LA UNIVERSidAd DEL VALLE y aHí apareció el grupo de solidaridad con los pueblos indígenas. Lo que decíamos en esa época era "la mejor forma de apoyar las luchas indígenas es adelantar las propias luchas"” (Fayad, 2000, entrevista).

Junto con Javier llegaron a Las Mercedes otros estudiantes de la universidad, entre ellos un personaje algo particular conocido como el Pastuso. Al revisar la entrevista realizada con Javier parece ser que nadie conoció -o al menos recuerda- el nombre del Pastuso. Sin embargo, las razones por las que el Pastuso llegó allí son importantes. Al parecer la verdadera preocupación de ese individuo era cortejar a una de las activistas más fervorosas del movimiento, lo cual lo ubicaba en una situación algo embarazosa. Según las descripciones recogidas, el Pastuso parecía entender con mucha dificultad, si acaso, el discurso del movimiento estudiantil. No estaba familiarizado siquiera con las líneas de los discursos que oscilaban entre el marxismo leninismo maoísmo y el trotskismo, por no mencionar toda una gama de variantes. Mucho menos entendía, por supuesto, el discurso del movimiento indígena y las contradicciones en la discusión entre el Cric y el naciente Movimiento de Autoridades Indígenas (Aico). Naturalmente, no era el único en tal condición. Existían tantas variantes de los discursos, tendencias y líneas como movimientos y miembros o simpatizantes, y el Pastuso no era el único que se acercaba a los movimientos sociales por primera vez en aquel encuentro de Las Mercedes. Pero de alguna manera sí representaba a aquellos que no podían encontrar su lugar en 


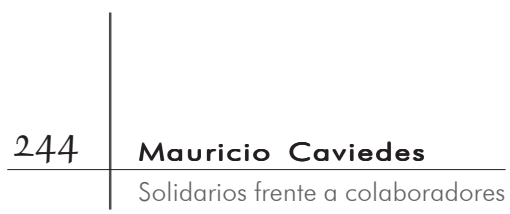

una discusión a la que habían llegado bastante tarde. Así que mientras el Pastuso seguía al objeto de su afecto -un afecto más bien platónico-, se esforzaba por elaborar explicaciones apresuradas en las que mezclaba un poco de todo, aplaudía a los oradores equivocados -al menos a los ojos de su amiga activista-, ahora reivindicaba a los indígenas por su logro en la recuperación de tierras, luego los calificaba de supersticiosos y les exigía subordinar su lucha a aquella de campesinos y obreros. La carrera que seguía en la universidad es tan desconocida como su nombre, al menos para aquellos que aportaron información sobre él, pero el asunto fundamental es que su entusiasmo, al principio obviamente fingido, fue transformándose vertiginosamente a lo largo del tiempo, hasta alcanzar consecuencias funestas.

A pesar de que la discusión entre el movimiento solidario junto al Movimiento de Autoridades y el Cric y sus colaboradores no indígenas tenía un trayecto previo, en el momento en que Javier Fayad llegó a Las Mercedes "la gente que apoyaba al movimiento indígena no se preocupaba tanto por estar de parte del Cric o de Aico" -nombre que adquirió el Movimiento de Autoridades en los años 1990- (Fayad, 2000, entrevista). Haciendo una retrospectiva, en el momento de hacer la entrevista Javier entendía la diferencia entre el Cric y Aico -la misma que entre colaboradores y solidarios- como una diferencia producto de modelos diferentes en condiciones diferentes. Para Javier, aunque el Cric se encontró en un momento contradictorio por haber adoptado una estructura organizativa sindical, esta estructura, que él prefiere entender como un modelo, era el resultado de una serie de condiciones políticas e históricas que exigían a la lucha indígena entrelazarse con la lucha obrera y campesina. De hecho, Javier recuerda, igual que muchos otros, que Trino Morales fue durante algún tiempo, a la vez que presidente del Cric, presidente de la secretaría indígena de la Asociación Nacional de Usuarios Campesinos (Anuc). Pero este modelo, aunque operativo en cierto momento de la lucha, fue también un obstáculo, en opinión de Javier, pues no era el resultado de formas propias de organización de las comunidades indígenas (Fayad, 2000, entrevista).

Ello permitirá entender mejor la situación del protagonista de esta historia, pues quien quiera que se acercase en aquel momento al movimiento indígena del Cauca tenía que insertarse en tal discusión. El Pastuso tuvo que hacerlo, en una situación poco 


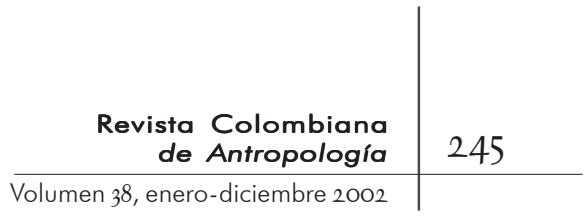

favorable. Por supuesto, él pudo haberse limitado, simplemente, a sus metas iniciales, pero por alguna razón inexplicable no fue así. Mientras el tiempo avanzaba en Las Mercedes, el Pastuso, quien inicialmente parecía no querer darle respiro en su persecución a la mujer de sus sueños, era visto cada vez menos en compañía de ella a la vez que absorto en los discursos que se escuchaban durante el día. Es difícil decir si ello fue producto de la habilidad de aquella joven para escabullirse o de un cambio de actitud de su persecutor; lo importante es el cambio radical en el Pastuso.

\section{¿REVOLUCIONARIO?}

Aúl Castro y Rubiela Álvarez tuvieron un aterrizaje similar en el Cauca. Aunque su llegada al movimiento solidario se prolongaría con el tiempo por medio de su participación en varios proyectos, pero fundamentalmente por la elaboración de su tesis de grado conjunta, entre un estudiante de ingeniería industrial y una de sociología. Algo inusual, pero al fin y al cabo resultado de aquel momento inusual. Mientras Raúl tenía una larga experiencia entre grupos estudiantiles que pregonaban ideas de transformación política y social, inspiradas en la izquierda marxista (Castro, 2000, entrevista), Rubiela se acercaba al asunto por primera vez. Ambos, Raúl y Rubiela, se conocieron al acercarse al movimiento solidario, resultado de lo cual comparten ahora una casa en las afueras de Bogotá, donde la entrevisté a ella, después de entrevistarlo a él en su oficina del centro de Bogotá. Y con ellos pude avanzar en mi reconstrucción de la historia del Pastuso.

Una de las razones que empujó a Raúl al grupo de solidaridad con los pueblos indígenas fue su frustración entre los grupos estudiantiles de izquierda de la universidad del Valle. En sus propias palabras, Raúl estaba cansado de "no hacer nada". Sentía que mientras más vehementes eran los discursos políticos de la universidad menos hacían quienes los sostenían, y que nada de ello trascendía políticamente. El movimiento indígena, sin embargo, estaba haciendo algo, estaba cambiando las cosas (Castro, 2000, entrevista). Pero justamente aquella experiencia hacía que Raúl volteara la mirada, con algo de desdén, a principiantes como 


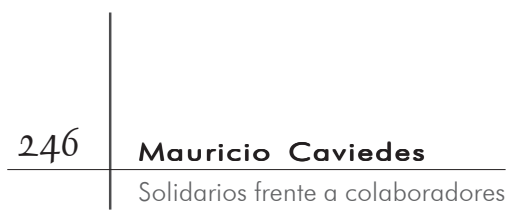

el Pastuso. A Raúl le desagradaba bastante el discurso improvisado e inseguro de quienes apenas empezaban a involucrarse pero querían fingir que no era así. De no ser por ello, tal vez su testimonio no hubiera permitido un acercamiento a la historia del Pastuso.

Por otra parte, igual que Javier, Raúl habla de la diferencia entre el Cric y Aico con cierta diplomacia, evitando culpar al Cric de consentir los intentos de los movimientos de izquierda tradicional de manipular al movimiento indígena, pero finalmente se ubica en la opción del Movimiento de Autoridades (Castro, 2000, entrevista). Rubiela, por su lado, entendía la discusión entre el Movimiento de Autoridades y el Cric como resultado, en parte, de la búsqueda de protagonismo de ciertos colaboradores, entre ellos Víctor Daniel Bonilla y Luis Guillermo Vasco, pero en su reflexión encuentra, finalmente, en el Movimiento de Autoridades una opción que permitió al movimiento indígena llevar una lucha autónoma a la vez que por la autonomía, sin dejar de hacerlo en relación con otros movimientos sociales (Álvarez, 2000, entrevista). Pero su llegada al movimiento se debió a la necesidad de acercarse a la posibilidad de participar en la transformación social, objeto importante de estudio de la sociología al que, sin embargo, la universidad no le había permitido ningún acercamiento. Pero al llegar al corazón del movimiento social se encontró totalmente ajena al discurso político (Álvarez, 2000, entrevista) y, al contrario que Raúl, ello la ubicó muy cerca de el Pastuso. Eso permitió reconstruir una parte adicional de los hechos desencadenados alrededor de ese sujeto.

De un momento a otro, el Pastuso había pasado de ser un observador pasivo a ser un orador enérgico, que defendía los derechos de las clases oprimidas y su consecución por medio de la lucha. En un par de noches había empezado a articular un discurso coherente, pero su situación aún era tambaleante. No había alcanzado a ser un líder, ni lo haría, pero su discurso bastante radical, como el de muchos militantes de la izquierda tradicional, acusaba a los indígenas de un atraso cultural que debían superar para apoyar la transformación política del país hacia el socialismo, aliándose a las clases obreras. La avidez de su oratoria atrajo de repente numerosos oídos. La mujer que hasta entonces le había sido esquiva ahora le seguía admirada, igual que una lista de muchas otras, pero el Pastuso no parecía tener más interés en ella. Por el contrario, parecía preocuparle más su 


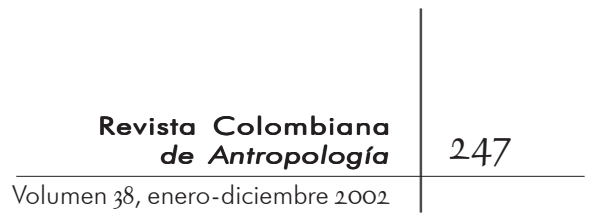

ubicación cerca a militantes del M-I9, presentes en aquel lugar, y a líderes sindicales y campesinos que simpatizaban con los estudiantes cuyo discurso apoyaba su posición de atraer al movimiento.

El Pastuso se había estrenado como activista en un par de noches. Pero otros habían hecho y harían algo similar. Lo que le convierte en una figura particular es el giro radical de su participación.

\section{¿INDIGENISTA?}

A uchos, como Raúl, Habían LLEgado a LAS COMUNIDADES INDíGEnas con una experiencia previa entre movimientos inspira1 dos en el marxismo. Pero muchos, a diferencia de él, tenían aún fe en el discurso de la izquierda ortodoxa, que veía en la población indígena potencial para su proyecto, pero la entendía subordinada a la acción política de la clase obrera, a cuyas búsquedas los indígenas debían aliarse (Gros, I99r: I37).

Los indígenas, sin embargo, se negaban a abandonar sus reivindicaciones territoriales y culturales, pero no ignoraban los reclamos que les hacían movimientos sindicales, estudiantiles e, incluso, armados. Y aunque la relación con el discurso de izquierda se había iniciado mucho tiempo atrás, las comunidades indígenas se insertaban en él con dificultad aún a principios de la década de 1980. En 1980, en la hacienda Las Mercedes se encontraban, al mismo tiempo, dos posiciones fundamentales entre los líderes indígenas. Mientras el Cric lideraba una amplia serie de cabildos y acumulaba otra de recuperaciones exitosas, el naciente Movimiento de Autoridades Indígenas -entonces llamado Gobernadores Indígenas en Marcha-, encabezado por los cabildos de Guambía y Jambaló, pero apoyado por otros cabildos páez -La Paila, Jebalá, Novirao y otros- proponía una estrategia diferente de movilización, de la que Las Mercedes era un resultado considerable y a punto de convertirse en el éxito más vistoso con el reconocimiento que le daría el entonces presidente Betancur. Ambas organizaciones eran el producto de la lucha indígena, de la intención de recuperación de territorios indígenas y del reclamo de derechos a sus tradiciones culturales ligadas a tales territorios, así como de una relación con movimientos y líderes de izquierda. 


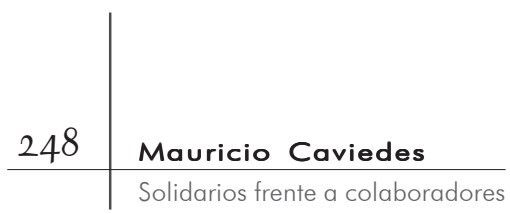

Pero estaban enfrentadas. El Cric reclamaba a su contraparte haber adoptado un discurso operativamente inútil, impuesto por un sector de colaboradores -que luego se definirían desde el movimiento de solidaridad- que proclamaba a las sociedades indígenas como pueblos - no razas- en defensa de derechos territoriales a la vez que tradicionales -el llamado derecho mayor-, impidiendo la posibilidad de interactuar con otros movimientos sociales (Tattay, 2000, entrevista). El Movimiento de Autoridades Indígenas reclamaba al Cric, por su parte, haber sucumbido, llevado por sus colaboradores no indígenas, a la izquierda ortodoxa, relegando la consecución del derecho mayor y el territorio indígena a la prioridad de la lucha revolucionaria (Gobernadores Indígenas en Marcha, I98I: 53).

En 1978, el Cric realizó un congreso en el que sus dirigentes presentaron una plataforma política. Esta plataforma fue rechazada por las comunidades con el argumento de que había sido elaborada sin consultarlas, pero también fue criticada por haber comprometido al movimiento indígena a una posición dependiente de una transformación del sistema capitalista (Cric, I978: 2, 4, 5). Sin embargo, los líderes de movimientos sindicales y otras organizaciones de izquierda presentes criticaron la plataforma propuesta, a su vez, acusándola de un pobre compromiso con otros sectores sociales y sus luchas políticas. El Cric definía entonces al movimiento indígena tanto como compuesto por pueblos explotados y dominados por los colonizadores, como sometido por las clases dominantes junto con otros sectores $\mathrm{y}$ clases sociales. Sin embargo, fluctúa entre la primera condición y la segunda en la medida en que ambas le exigen compromisos en conflicto (Cric, 1978).

Incluso, años antes, el Cric se debatía en su relación con la Asociación Nacional de Usuarios Campesinos, en tanto declara la importancia de seguir la lucha junto a otros sectores sociales -junto a la Anuc en este caso-, pero al mismo tiempo recuerda que la lucha no puede renunciar a los cabildos como base de la misma, ni al fortalecimiento de estos, pues su sentido está justamente en la recuperación de los resguardos y su base en formas propias de organización. Lejos de estar al amparo de la lucha campesina (Archila, 1997: I3), el Cric se encontraba en una situación ambigua, pues mientras la Anuc buscaba captar al movimiento indígena, este esperaba mantener un lazo con el movimiento campesino, sin perder su autonomía (Cric, 1975: 5). 


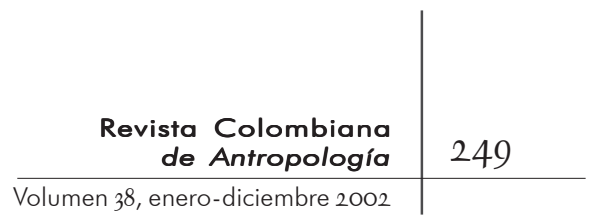

De vuelta a I980, el Movimiento de Gobernadores Indígenas en Marcha reclamaba al Cric haberse entregado a la izquierda y haber abandonado los principios de la lucha indígena. Pero, ¿qué estaba sucediendo a los ojos de las comunidades?; ¿qué sucedía con los terrajeros que no estaban en el comité ejecutivo, que luchaban en las recuperaciones, que eran perseguidos pero no eran parte del liderazgo? En el resguardo de La Laguna, Siberia -municipio de Caldono-, José Roberto Chepe, hoy maestro de la escuela bilingüe de su resguardo, recuerda cómo él y otros empezaron a apoderarse, entender y utilizar una lógica heredada de los movimientos de izquierda que en aquel momento les rodeaban para perseguirlos o apoyarlos.

Estando en una manifestación sindical, a la que él había sido invitado con otros miembros del cabildo del resguardo como representantes del movimiento indígena, Roberto resultó, por accidente, de pie como orador frente a la multitud, y en medio de la duda, de un discurso algo tartamudo, introdujo una palabra que entendía vagamente, pero que para su sorpresa produjo aplausos, júbilo y celebraciones por lo que se interpretó como apoyo mutuo entre el movimiento indígena y el sindical. La palabra que había pronunciado Roberto era imperialismo. En aquella época él mismo no sabía con claridad lo que aquello quería decir, pero con el tiempo imperialismo, al igual que clase social se hicieron conceptos familiares, si bien no para toda la comunidad, sí para líderes regionales y locales, mientras la comunidad era consciente de la necesidad de una relación con otros movimientos sociales, lograda por medio del manejo que los líderes poseían de aquel discurso (Chepe, 2000, entrevista).

Pero no hay que alejarse de la historia central. Si Roberto y otros indígenas como él adquirieron una comprensión de aquel discurso fue en espacios como el de Las Mercedes, donde se mezclaban diferentes discursos y diferentes organizaciones y movimientos sociales se acercaban al movimiento indígena, en algunos casos para captarlo y en otros para apoyarlo. Y es allí donde alguien como el Pastuso podía encontrarse sentado junto a alguien como Roberto, quien recuerda cómo los estudiantes, particularmente, insistían en que las comunidades indígenas debían abandonar sus prácticas supersticiosas en favor de la lucha. Pero recuerda también que aquello cambió a medida que las recuperaciones avanzaron y, como confirma Javier Fayad, distintos movimientos sociales tuvieron que abrir espacio en 


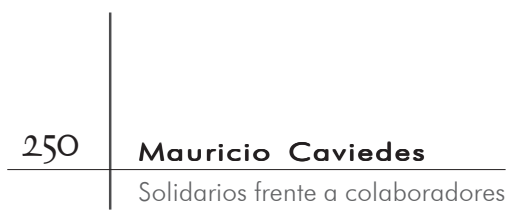

sus discursos para referirse a las luchas indígenas (Fayad, 2000, entrevista).

Igual que Rubiela, es probable que alguien como el Pastuso hubiera tenido profundas dificultades para diferenciar la posición del Movimiento de Autoridades de la del Cric. Sólo la interacción con los indígenas terrajeros y el contacto con quienes conformaban la lucha indígena podía permitir una comprensión mutua. Con el tiempo, el movimiento solidario elaboraría una posición al respecto: para apoyar al movimiento indígena era necesario conocer a las comunidades indígenas y la situación de los terrajeros, pues no se trataba de apoyar por principio. Esto fue el resultado de discutir si el logro de las búsquedas políticas sería consecuencia de la introducción del desarrollo occidental en las comunidades indígenas, una pregunta que la antropología enfrenta desde mucho antes, pero que en el Cauca no se formuló como una pregunta académica sino como una que debía resolverse para el avance de las luchas. Conocer era también una opción opuesta a una de las exigencias de la izquierda armada: aceptar lo que nos une para fortalecer la lucha y, una vez lograda la transformación política del país, discutir las diferencias (Rojas, 2000, entrevista).

En la reconstrucción de la historia del Pastuso, que pude hacer mediante las entrevistas con algunos solidarios, parece claro que en la recuperación de Las Mercedes él debió aceptar pronto el cuestionamiento que el movimiento indígena hizo a la izquierda ortodoxa: admitir que los pueblos indígenas no renunciarían al futuro, que una alianza en las luchas no podía sacrificar las particularidades del movimiento indígena mientras se alcanzaban los logros de un movimiento obrero o campesino (Rojas, 2000, entrevista). Así, el discurso del Pastuso varió tan pronto como su popularidad en las asambleas. Su cambio fue el resultado de una tensión creciente por diferencias entre las organizaciones indígenas, que tomaría años cambiar.

\section{¿COLABORADOR O SOLIDARIO?}

C I BIEN ES CIERTO QUE ESTA NO FUE UNA PREGUNTA HECHA CONSCIENtemente (Fayad, 2000, entrevista), entenderla permitirá acercarse a la manera en que el movimiento indígena se construyó 


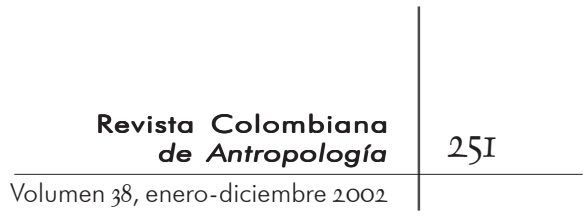

en el Cauca. Lo que se encontraba en juego en aquel momento no era simplemente la subordinación de las organizaciones indígenas a las organizaciones de izquierda ortodoxa, sino la aceptación del hecho de que el indígena existe y de que su situación marginal no se explica por una condición de clase. Las posiciones al respecto tenían que ver con el proceso de insertarse en esta reflexión.

Ana Beatriz Tamayo describe la relación del movimiento solidario con el movimiento indígena como de doble vía. Lo que quiere decir que el movimiento solidario no existía al servicio del movimiento indígena sino paralelo a él. Debía alimentar al movimiento indígena tanto como a expectativas de transformación social de los solidarios (1984: 156). Pero los solidarios no eran un grupo políticamente homogéneo, y aunque el movimiento solidario no exigía renunciar a filiaciones políticas previas, aparentemente logró que distintas líneas políticas -del liberalismo al trotskismo- permanecieran sin interponerse en el avance del movimiento (Rojas, 200o, entrevista). Es por ello que algunos solidarios prefieren hablar de un pensamiento crítico en vez de una posición de izquierda, aun cuando el acercarse al movimiento indígena, después de años de marginación política indígena en manos del conservatismo y el liberalismo, llevaba implícita una búsqueda alternativa (Fayad, 2000, entrevista). Esta confluencia de líneas políticas debía lograrse, justamente, en el ejercicio de conocer (Rojas, 2000, entrevista).

En 1980, María Teresa Findji, Álvaro Velasco, Luis Guillermo Vasco y Víctor Daniel Bonilla, todos miembros del movimiento solidario, presentaron en un simposio, en el congreso de antropología en Medellín, una propuesta política y metodológica, resultado de la experiencia del movimiento. En ella Vasco introduce una reflexión acerca del papel del científico social frente a las comunidades indígenas, criticando la posición del investigador como sujeto frente a sus objetos de estudio -los indígenas-, exigiendo la transformación de tales relaciones -que reproducen las relaciones de dominación existentes entre sociedad nacional y sociedad indígena- a partir de una nueva perspectiva política, en la que las metas políticas del antropólogo se apoyan en el proyecto político indígena y viceversa, creando una relación entre sujetos investigadores, superando las encrucijadas de la investigación/acción/participación (Vasco, I983), que, como revela la ponencia de Álvaro Velasco, fue el principio metodológico 


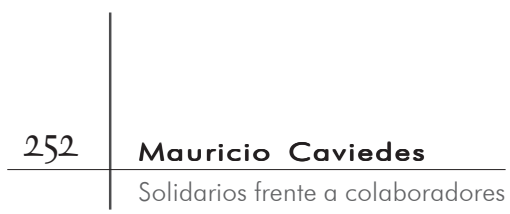

del cual partieron los ejercicios investigativos de los solidarios -en este caso los mapas parlantes, una serie de mapas que representaban la historia del territorio indígena desde la colonia hasta el presente- (Velasco, I983).

Sólo el movimiento solidario formuló la intención de conocer como parte de la lucha, pero conocer -no como producción de conocimiento, sino como interacción intelectual entre movimientos y actores sociales- fue el ejercico al cual se vieron abocados, voluntaria o involuntariamente, quienes se involucraron con la lucha indígena en el Cauca como solidarios o colaboradores. Es por ello que en la actualidad algunos solidarios -Vasco, Rojas y Rappaport, cercana al movimiento solidario- se encuentran trabajando junto al Cric, pero esta situación tomó tiempo para desarrollarse (Caviedes, 2000: 78).

Para entender ese desarrollo, en el proceso de recoger estas memorias intenté armar la historia del personaje que se me presentó en pedazos entre los testimonios de mis entrevistados. Junto con ellos, entre viejos documentos, encontré un manuscrito, que transcribo, con el cual quiero dar fin a lo que sé del Pastuso.

\section{CONSTRUIR EL MOVIMIENTO}

Transcripción del fragmento anónimo (sin fecha):

La asamblea del núcleo se acaba hoy. Se han preparado estrategias para las recuperaciones, pero los guambianos dicen que los solidarios sólo podemos apoyarlas discutiendo las estrategias y denunciando la situación. No quieren que nosotros entremos a las recuperaciones. Tal vez sea mejor así para mí, al menos después del susto de ayer. Muy pocos durmieron después de la asamblea de ayer (que se convirtió en un debate sin fin) y lo que pasó después. Cuando Palechor, uno de los líderes del Cric, decidió presentar la posición del Cric frente a la recuperación de Las Mercedes, admitió su importancia, pero le reclamó al cabildo de Guambía y Jambaló que la mayoría de las recuperaciones habían sido gracias al Cric. Bastó que dijera eso frente a todos los que vinieron apoyando al cabildo de Guambía y Jambaló para que reventara una polémica que pensé que no se iba a acabar. Todos los líderes se levantaban para hablar. Todo el mundo opinaba y en realidad yo no entendía lo que estaba pasando. 


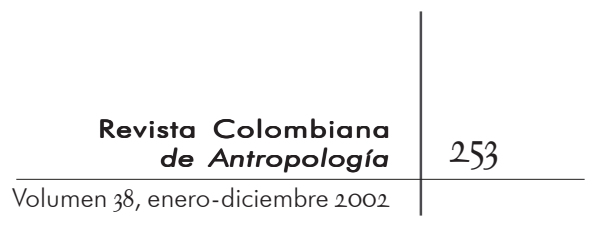

Cuando llegué aquí, ni siquiera era consciente de que había diferencias entre los cabildos, pensé que en la asamblea se iban a formular estrategias para todas las recuperaciones. Supongo que yo mismo no sabía lo que eso quería decir, pero uno siempre piensa en esas cosas como si en un movimiento social todos estuvieran en lo mismo. Cuando fui a esas reuniones del movimiento solidario en la universidad, varias veces escuché hablar sobre las diferencias entre el movimiento de Gobernadores Indígenas en Marcha y el Cric, pero nunca entendí que lo que Bonilla y Vasco y María Teresa Findji defendían era una posición de disidencia del Cric sino hasta ayer. Lo raro es que muchos de los que llegamos de la universidad para apoyar esta recuperación estamos apenas entrando en la discusión. Lo peor de todo fue cuando me pidieron que fuera relator de la asamblea de ayer. ¿Cómo podía recoger la discusión si apenas entendía lo que se estaba discutiendo?

Entonces empezó la parte más complicada, porque de repente había dos discusiones paralelas. Mientras los guambianos se peleaban con Palechor por las recuperaciones, Bonilla y Vasco peleaban con Pablo Tattay [colaborador del Cric] sobre la estrategia de recuperación. Bonilla y Vasco decían que entrar finca por finca para presionar al dueño a que vendiera al Incora, que luego volvería a venderle al cabildo, era olvidar que esas tierras eran originalmente de los indios. Tattay respondía que entrar a las fincas y luego presionar para que esas tierras fueran reconocidas como indígenas, peleando la legitimidad de las escrituras de los resguardos (que era la propuesta del resguardo de Guambía y Jambaló), no era una estrategia práctica. Decía que nadie reconocería unas escrituras notariales de principios de siglo. Al rato Bonilla estaba diciendo que la recuperación con las escrituras era parte de la estrategia de luchar por "derechos" como "pueblos indígenas", pero Palechor respondía que esos eran discursos académicos, Vasco los acusaba entonces de haberse entregado al M-I9. Uno de los guambianos, Muelas, le decía a Pablo que estaban actuando como "politiqueros". Sólo recuerdo fragmentos de las discusiones.

Fue ahí cuando interrumpió el Pastuso. Yo no sé mucho de él, pero nunca lo creí alguien realmente preocupado o comprometido con esto. Más me parecía un charlatán y siempre pensé que estaba aquí sólo por jugar al mesías. Pero cuando lo escuché hablar ayer, simplemente me sentí inspirado. Mientras hablaba tuve esa sensación de que esa idea indefinible de "la utopía" de repente adquiría sentido y era tan clara que casi podía atraparla entre mis manos. Lo escuché decir que nosotros mismos estábamos ahogando al movimiento. Que esta discusión no tenía sentido ¿acaso no estamos todos aquí por lo mismo?, preguntó, y luego dijo que no era sólo un asunto de indios. Dijo que la emancipación y el derecho de todos los pueblos se estaba jugando aquí, que por eso había gente no indígena aquí. Y finalmente dijo que había que encontrar una forma de jugar juntos. Y entonces vino la peor parte. 


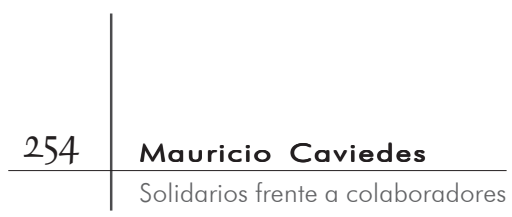

En la recuperación había infiltrados de tal vez todos los movimientos armados, miembros de organizaciones campesinas, sindicatos, organizaciones estudiantiles y casi cualquier organización política imaginable. Así que no sé cómo los terratenientes organizaron aquel intento por sacarnos, pero lo cierto es que antes de que el Pastuso terminara de hablar, una avalancha literal de ganado que se extendía por el horizonte hasta donde la vista alcanzaba, en una carrera desesperada, se vino encima de quienes estábamos acantonados en la recuperación de Las Mercedes. No hubo tiempo para pensar en nada, sino correr. Pero antes de que reaccionásemos, el Pastuso saltó sobre Vasco y, arrebatándole de las manos las escrituras notariales, corrió en dirección hacia la avalancha vacuna gritando, mientras agitaba los papeles en el aire: "iEsto no significa nada!”.

Para entonces el ganado estaba tan cerca y venía a tanta velocidad, que ni siquiera Vasco vaciló para recuperar los papeles, todos corrimos despavoridos sin mirar atrás, sintiendo el piso temblar bajo nuestros pies por la incontenible fuerza de aquel ganado. Corrimos hacia algún árbol y yo tuve la suerte de que un guambiano me ofreciera su mano para escalar un árbol y esperar ahí, temblando (el árbol y nosotros), mientras las vacas corrían, se estrellaban unas contra otras y acababan con todo a su paso. Y no bajamos de los árboles sino hasta que anocheció...

\section{¿IMAGINACIÓN HISTÓRICA?}

l CORROBorar la VERACIDAD DEL TEXTo, VASCO AFIRMÓ QUE TATTAY nunca había estado en la discusión (2002, comunicación personal). Tattay dijo que él no había discutido con Vasco o Bonilla (Tattay, 2002, comunicación personal). También que en Las Mercedes había sólo algunos toros de lidia (Vasco, 2002, comunicación personal), aunque Lucero Gómez describió una manada de ganado que arremetió contra la asamblea, pero ella ubicó el hecho en otro lugar del Cauca (Gómez, 2000, comunicación personal). Pero la historia es resultado de testimonios de aquellos que estuvieron involucrados en los procesos de recuperacion de tierras del movimiento indígena en el Cauca, entre las décadas de 1970 y I980. El personaje, real o ficticio, se envuelve en la atmósfera, sufre las mismas confusiones, y finalmente se ve obligado a tomar decisiones y posiciones, como sucedió con quienes entrevisté, en especial con Fayad, Castro y Álvarez, cuya experiencia y posición sobre la lucha y el movimiento solidario difieren de aquella de Vasco y Bonilla, pues aunque reclutados 


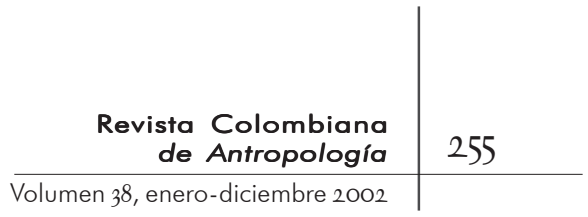

por estos nunca fueron disidentes del Cric. Algo similar sucedió conmigo, en una búsqueda que exigía de mí una posición -aún lo hace-. Al analizar el texto "La formación de la clase obrera inglesa" de Thompson, Rosaldo sostiene que el estilo melodramático de Thompson es una estrategia de descripción histórica en la que Thompson se sitúa él mismo -y exige al lector hacerlo- del lado de aquellos sobre quienes escribe, evitando convertirlos en "objetos de estudio" (Rosaldo, I99I: I32). Este fragmento -ficticio o real-no es un capricho literario. Es una posición frente a la discusión y una exigencia a usted, amigo lector. También es un intento por trascender formas de escritura que reduzcan este texto a una comunidad académica, porque su intención es tanto ser un aporte a la antropología como al movimiento indígena, reconstruyendo una reflexión que ha transformado a ambos. Tal vez, algún día, nuevas generaciones de líderes indígenas lean estas líneas.

\section{Antropología y MOVIMIENTO INDÍGENA}

S POSIBLE QUE TUliO RojAs (2000, ENTREVISTA) TUVIESE RAZÓN AL - decir que la diferencia entre el Cric y el Movimiento de Autoridades fue que el segundo decidió llevar la lucha ligado a otros movimientos sociales pero de manera autónoma, mientras el Cric lo hizo entrelazándose con una izquierda más ortodoxa (Rojas, 2000, entrevista). Es definitivamente cierto, que "el Cric son las comunidades organizadas y en lucha", como declararon las mismas a finales de los años I970 (Bonilla, 2000, entrevista; Vasco, 2002: 2I7). Pero si el Cric realmente abandonó sus principios por articularse a la izquierda, ¿por qué continuó siendo importante para una gran cantidad de comunidades y participó en muchas otras recuperaciones? Y si los cabildos de Guambía y Jambaló junto a los solidarios creían realmente que el Cric eran las comunidades organizadas y en lucha, ¿por qué crear una organización paralela?

Mientras los muchos solidarios y colaboradores, así como los cabildos de Guambía y Jambaló, estaban envueltos en la discusión sobre cuál era la posición legítima que debía asumir el movimiento indígena, las comunidades estaban llevando a cabo una discusión por su propia cuenta, en la que con discurso o sin 
él definieron su papel en la lucha, en las recuperaciones y en su relación con otros movimientos sociales. En el resguardo de La Laguna, la comunidad entiende que la recuperación del resguardo ocurrió gracias al Cric, que la escuela bilingüe -elemento central de la vida comunitaria- existe gracias al Cric, incluso el cabildo es el resultado de la gestión del Cric. Pero quienes estuvieron en la recuperación fueron ellos mismos, quienes construyeron y mantienen la escuela son ellos mismos. Ellos fueron el Cric, en la medida en que se comprometieron con las reivindicaciones que reclamó en su nacimiento. Si el comité ejecutivo se alejó de las comunidades, provocando la separación de algunos cabildos, las comunidades fueron las que moldearon la reconstrucción del Cric para mantener una lucha, aliada a otros movimientos, sin renunciar a las particularidades por las que el movimiento indígena en el Cauca había nacido. Reducir el movimiento indígena a la discusión entre solidarios y colaboradores sería un error definitivo, como me advirtió Tattay (2000, entrevista). Pero en ella hay profundas pistas sobre el papel de la antropología en el proceso.

Gros narra cómo su acercamiento a los movimientos sociales fue motivado por una aproximación -algo titubeante- a la teoría marxista, que parecía apropiada a la descripción de la Colombia rural de las décadas de ig60 y I970. Ese acercamiento lo llevó, lentamente, al movimiento indígena de Cauca (2000: I9, 20). Pero una vez allí una mezcla de corrientes teóricas le inclinaron a definir el movimiento desde el concepto de identidad, replanteándolo hacia "una acción: aquella de un grupo dado, de un actor que se moviliza. La identidad se vuelve una relación, se remite a otros actores, a diferentes poderes y a una totalidad" (Gros, 2000: 40). Se trata de una identidad dinámica, que sólo era posible entender en interacción con el estado y otros movimientos sociales.

Pero el replanteamiento de Gros sobre la identidad es el que habían elaborado previamente las comunidades y sus colaboradores o solidarios. Y va mas allá, cuando el movimiento indígena, que confronta al estado y su política frente a los indígenas como comunidades marginales, confronta también a otros movimientos sociales apropiando sus discursos sobre transformación de la sociedad, sobre confrontación a la clase "burguesa" y al "sistema capitalista" -como en la plataforma política del Cric presentada en I978-, pero matizándolo con un discurso mítico, 


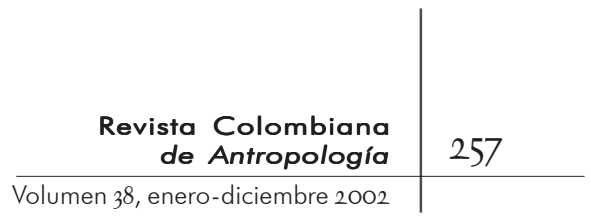

con cabildos, con una relación tradicional y ancestral con la tierra -sin la que el indio no existe-. Aparece entonces el discurso de "recuperar la tierra para recuperarlo todo" (Castro, 2000, entrevista; Gobernadores Indígenas en Marcha, I98I). Un reclamo no sólo jurídico y económico, sino la reivindicación de una situación cultural y la expectativa de decidir, autónomamente, sobre el futuro de tal situación; la posibilidad de mantener y transformar autónomamente hacia el futuro esas lenguas, esas tradiciones, esas formas de pensamiento cuyo presente era el resultado de una serie de relaciones de poder desigual entre comunidades indígenas y sociedad nacional. Una identidad que volvía al pasado y ligaba a la tierra, para proyectarse hacia el futuro y a la sociedad nacional

La intención de este texto no es demostrar que Vasco y Bonilla habían descubierto a principios de la década de 1970 lo que años más tarde empiezan a sostener los autores posmodernos. Sostengo que la reflexión sobre la relación entre sociedades indígenas y sociedad nacional no se llevó a cabo sino debido a la necesidad de transformar las relaciones de poder entre ambas y dentro de ambas, y que la antropología, contrario a lo que afirma Vasco (2002: 172) hizo parte de ello, si bien no siempre gracias a los antropólogos mismos. Mientras se cuestionaban las relaciones de clase en la sociedad nacional, se cuestionaba también la posición de indígenas y campesinos en el esquema de clases (Gros, I991: 19, 20) que, a su vez, se extendía hacia la relación entre bases y líderes, e incluso a un cuestionamiento de relaciones de poder entre movimientos sociales. La reflexión antropológica permitió en este espacio crear una comunión entre proyectos políticos opuestos -uno modernizante, otro tradicional- y una comunión entre movimientos sociales y actores sociales -intelectuales, campesinos, sindicalistas e indígenas-. Y esta reflexión, que se dio en el campo -y no en las oficinas de académicos ingeniosos-, empezó a manifestarse en los textos de algunos antropólogos (Vasco, 1980; 2002: 202; Rapapport, I990: 25; Gómez, 2000: 30-33).

En la actualidad, las posiciones del Cric y Aico han cambiado, y mientras el Movimiento de Autoridades se desvanece en la contienda electoral el Cric adelanta una poderosa política de educación que le permite proyectarse hacia el futuro sin diluirse en el estado, como después de la constitución de I99I ha sucedido con parte del movimiento. Y aquellas diferencias entre 
solidarios y colaboradores parecen superarse en la medida en que quienes alguna vez estuvieron una posición disidente-como Vasco y Rojas- se han alejado del Movimiento de Autoridades para aceptar y hacer parte hoy del proyecto de educación indígena del Cric. Esta política de etnoeducación, que Vasco critica hoy como parte de la captación del movimiento (Vasco, 2002: I6I, I62), es justamente el espacio en donde continúa la lucha con mayor fuerza, pues es allí donde, al confrontar el conocimiento indígena y la educación occidental, los maestros indígenas tienen y ejercen la posibilidad de superar la relación desigual de poder entre sociedad indígena y sociedad nacional. Ello no se da sin problemas, naturalmente (véanse Rappaport, I998: 27; Gros, 2000: II), pero ya Gramsci había anotado que la educación puede ser tanto un espacio de imposición de la ideología del estado como de confrontación y transformación de la misma (Gramsci, I998: 82-84). He aquí un nuevo reto para la antropología, que el movimiento indígena ha decidido aceptar. ¿Lo harán los antropólogos?

\section{BibliografíA}

Archila, Mauricio. I997. "Protesta social y estado en el frente nacional". En Controversia. I70. Cinep. Bogotá.

Arocha, Jaime y Friedemann, Nina de (editores). i984. Antropología en Colombia. Un siglo de investigación social. Etno. Bogotá.

Bonfil, Guillermo. ig8r. Utopía y revolución. El pensamiento político contemporáneo de los indios en América Latina. Nueva Imagen. México.

Bonilla, Víctor Daniel. I982 [I977]. Historia política de los paeces. Colombia Nuestra Ediciones.

Caviedes, Mauricio. 2000. "Antropología y movimiento indígena”. Tesis. Universidad Nacional de Colombia. Bogotá.

Consejo Regional Indígena del Cauca (Cric). i975 (mayo). Unidad Indígena. 5. Popayán.

— . 1978 (agosto). Unidad Indígena. Popayán.

GOBERNADORES INDíGENAS EN MARCHA. I98I. "Cómo recuperamos nuestro camino de lucha“.

Gómez, Herinaldy. 2000. "De los lugares y sentidos de la memoria”. 


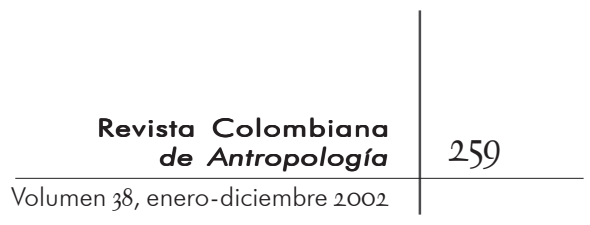

En Marta Zambrano y Cristóbal Gnecco (editores). Memorias hegemónicas, memorias disidentes: el pasado como política de la historia. ICANH-Colciencias-Universidad del Cauca. Bogotá.

Gramsci, Antonio. [198I] 1998. La alternativa pedagógica. Distribuciones Fontamara. México, D. F.

Gros, Christian. I99I. Colombia indígena. Identidad, cultura y cambio social. Cerec. Bogotá.

-2000. Políticas de la etnicidad: identidad estado y modernidad. ICANH. Bogotá.

Jimeno, Myriam. 2000. "La emergencia del investigador ciudadano: estilos de antropología y crisis de modelos en la antropología colombiana”. En Jairo Tocancipá (editor). La formación del estado nación y las disciplinas sociales en Colombia. Universidad del Cauca. Popayán.

Ortner, Sherry B. I994. "Theory in anthropology since the sixties". En Culture/Power/History. Princeton University Press. Princeton.

Pineda Camacho, Roberto. 1984. "La reivindicación del indio en el pensamiento social colombiano I850-1950". En Jaime Arocha y Nina S. de Friedemann. Antropología en Colombia. Un siglo de investigación social. Etno. Bogotá.

RAPAPPORT, JOANNE. 1998. "Hacia la descolonización de la producción intelectual indígena en Colombia”. En María Lucía Sotomayor (editora). Modernidad, identidad y desarrollo. ICANH. Bogotá. . I990. The politics of memory. Cambridge. University Press. Cambridge.

Rosaldo, Renato. [1989] i99I. Cultura y verdad. México. Grijalbo.

Tamayo, Ana Beatriz. i986. "Jambaló: autonomía o muerte". Tesis. Universidad de Antioquia. Medellín.

Uribe Tobón, Carlos A. 1980. "La antropología en Colombia". En América indígena. Volumen XL: 2.

VAsco, Luis Guillermo. 1980. "La lucha guambiana por la tierra: ¿indígena o campesina?”. En Revista de letras de tierra. 2. Bogotá.

. I983. "Algunas reflexiones epistemológicas sobre la utilización del método etnográfico en el trabajo de campo". En Boletín de Antropología. Volumen V: I7-I9. Tomo II. Universidad de Antioquia. Medellín.

. 2002. Entre selva y páramo, viviendo y pensando la lucha india. ICANH. Bogotá. 
Velasco, Álvaro César. I983. "Introducción al pensamiento jurídico de los indígenas". En Boletín de Antropología. Volumen V: I7I9. Tomo II. Universidad de Antioquia. Medellín.

\section{Entrevistas}

Rubiela ÁlVAREz, 2000.

Víctor Daniel Bonilla, 2000.

Raúl Castro, 2000.

José Roberto Chepe, 2000.

JAVIER FAYAD, 2000.

LuCero Gómez del Corral, 2000

Pablo Tattay, 2000.

Tulio Rojas Curieux, 2000.

Luis Guillermo Vasco, 2000. 